University of Nebraska - Lincoln

DigitalCommons@University of Nebraska - Lincoln

$7-2004$

\title{
The Sweet Tooth of Adult Parasitoid Cotesia rubecula: Ignoring Hosts for Nectar?
}

\author{
Gitta Siekmann \\ Federal Biological Research Centre for Agriculture and Forestry, Germany, g.siekmann@bba.de \\ Michael A. Keller \\ University of Adelaide, Australia, mike.keller@adelaide.edu.au \\ Brigitte Tenhumberg \\ University of Nebraska - Lincoln, btenhumberg2@unl.edu
}

Follow this and additional works at: https://digitalcommons.unl.edu/bioscifacpub

Part of the Life Sciences Commons

Siekmann, Gitta; Keller, Michael A.; and Tenhumberg, Brigitte, "The Sweet Tooth of Adult Parasitoid Cotesia rubecula: Ignoring Hosts for Nectar?" (2004). Faculty Publications in the Biological Sciences. 122. https://digitalcommons.unl.edu/bioscifacpub/122

This Article is brought to you for free and open access by the Papers in the Biological Sciences at DigitalCommons@University of Nebraska - Lincoln. It has been accepted for inclusion in Faculty Publications in the Biological Sciences by an authorized administrator of DigitalCommons@University of Nebraska - Lincoln. 
Published in Journal of Insect Behavior 17:4 (July 2004), pp. 459-476.

Copyright () 2004 Springer Science+Business Media, Inc. Used by permission.

Accepted April 19, 2003; revised March 30, 2004.

\title{
The Sweet Tooth of Adult Parasitoid Cotesia rubecula: Ignoring Hosts for Nectar?
}

\author{
Gitta Siekmann, Michael A. Keller, and Brigitte Tenhumberg \\ Department of Applied and Molecular Ecology, The University of Adelaide, \\ Waite Campus Private Bag 1, SA 5064 Glen Osmond, Australia
}

Corresponding author - G. Siekmann. Present address: Institute for Plant Protection in Horticulture, Federal Biological Research Centre for Agriculture and Forestry, Messeweg 11-12,

38104 Braunschweig, Germany; email g.siekmann@bba.de

\begin{abstract}
Investing time and energy into survival and reproduction often presents a trade-off to many species of animals. In parasitic wasps, both hosts and sugar sources contribute to the forager's fitness but are often found in different locations. The decision to search for hosts or for food can have a strong impact on fitness when the forager's lifetime is short and resources are not abundant. We investigated the tendency of flowers and hosts to attract 1-day-old female Cotesia rubecula Marshall (Hymenoptera: Braconidae) with different feeding histories in a wind tunnel. Only well-fed wasps exhibited a preference for hosts. In comparison, unfed wasps visited hosts and flowers in equal proportions. Feeding experience had a strong impact on the searching behavior and the number of landings on both resources. Host and food stimuli seem to be equally attractive to hungry parasitic wasps such as C. rubecula. We expect that under field conditions the time available for active food searching in female C. rubecula is short and influenced by the presence of hosts.
\end{abstract}

Keywords: foraging behavior, food experience, flowers, energy state, conservation of natural enemies

\section{Introduction}

Parasitic wasps are ideal subjects to study the trade-off between two competing foraging strategies that influence reproduction or survival. Parasitic 
wasps lay eggs in or on a discrete host and often feed on sugary food. Sugar feeding usually results in a greater longevity that is often positively correlated with a higher fecundity (Wolcott, 1942; Leius, 1961; Hagley and Barber, 1992; Morales-Ramos et al., 1996; Heimpel et al., 1997). A conflict between searching for hosts or food arises when these resources are found on different plants and a female parasitoid has nearly exhausted her energy reserves but still has eggs left to lay. If both food sources and hosts are available, female wasps should alternately search for food and hosts to aim for maximum lifetime reproduction (Sirot and Bernstein, 1996; Casas et al., 2003). The decision to search for food instead of hosts depends on factors such as energy state, experience in food searching, egg load, distance to and abundance of food sources (Jervis et al., 1996; Heimpel et al., 1998; Lewis and Stapel, 1998). In this study energy state and food experience were investigated because they had been identified as major driving forces on the preference for hosts or food in parasitic wasps (Lewis and Takasu, 1990; Wäckers, 1994; Rivero and Casas, 1999).

Parasitic wasps use olfaction to locate nectar sources (Leius, 1967; Lewis and Takasu, 1990; Wäckers and Lewis, 1994; Patt et al., 1999) and to some degree visual cues (Wäckers, 1994). There are only a few studies on how parasitic wasps locate potential nectar sources in the presence of hosts. Given the choice between odor cues from sugar sources or hosts, the majority of unfed parasitic wasps were moving towards a flower (Wäckers, 1994) or scented artificial sugar solutions (Lewis and Takasu, 1990; Takasu and Lewis, 1993; Takasu and Lewis, 1996). These choice experiments were carried out in an olfactometer apparatus with flowers and hosts within walking distance of unfed wasps (Wäckers, 1994) or in a wind tunnel arena within flying distance of food-experienced wasps (Lewis and Takasu, 1990; Takasu and Lewis, 1993). The first case reveals insight into the wasp's preferences in a location that provides both hosts and nectar at the same time. However, nectar and hosts are often found on different plants and require traveling between locations. The process of flying to a nectar plant makes decisions more complex because (1) there is a risk of losing track of the host site, (2) flying to the food source costs precious energy, and (3) the energy reward of the food source may be very low or totally lacking. Lewis and Takasu (1990) and Takasu and Lewis $(1993,1996)$ have demonstrated in their wind tunnel studies that hungry wasps with food experience still prefer food to hosts even if they have to fly to the resources. However, no research has been carried out on the response of nectar-naïve and nectar-experienced wasps being given a choice between flowering plants and plants with hosts, both within flying distance. This field situation not only resembles a more natural field but also reveals the choices of nectar-naïve wasps when resources are within flying distance. Parasitic wasps often forage in agricultural areas where hosts and food are spatially separated: hosts occur on crop plants while nectar producing plants might occur at some distance, perhaps only at the periphery of crop fields. 
This study aims to investigate the influence of energy state and nectar experience of a parasitic wasp on her choice between flying to plants with hosts or those with flowers. To analyze the choices made, the sequence and duration of behavioral acts were recorded as well. For example, the extent to which a wasp would fly, walk, or sit still can indicate if coordinated searching behavior is employed rather than random behavior. Also, flowers may be located in a different fashion than hosts which could be traced by a comparison of the nature of behavioral acts employed in foraging.

\section{Materials and Methods}

\section{Insect and Plant Rearing}

Cotesia rubecula Marshall (Hymenoptera: Braconidae) was selected as the focus of this study because it feeds solely on sugar and has a high potential fecundity, and female life expectancy is greatly influenced by sugar consumption (Nealis, 1986, 1990; Sengonca and Peters, 1993; Wäckers and Swaans, 1993). Starved C. rubecula have been found to respond to flowers in the presence of hosts in olfactometer experiments and to yellow colors in flight chambers (Wäckers, 1994). Females feed readily on sugar sources such as honey, honeydew, and floral nectar, thereby increasing their lifespan up to 2- to 10-folds (Sengonca and Peters, 1993; Wäckers and Swaans, 1993). Without feeding, females usually die after 2-3 days at $25^{\circ} \mathrm{C}$ (Wäckers and Swaans, 1993). Host feeding does not occur in this species. C. rubecula is a solitary parasitoid of the cabbage white butterfly Pieris (syn. Artogeia) rapae Lineaus (Lepidoptera: Pieridae) feeding on Brassica plants (see references in Cameron et al., 1995). Females usually oviposit a single egg inside the host's body and the developing parasitoid larva consumes host hemolymph and tissue. Female $C$. rubecula have predominantly pro-ovigenic (a large number of small, hydropic eggs, no protein source required for maturation) and some synovigenic characteristics (not all eggs fully mature at eclosion) (i.e., as Venturia canescens in Fletcher et al., 1999), maturing about 100 eggs within their first 3 days of life. However, Jervis et al., (2001) reviewed the mode of egg development and defined all parasitoid species that emerge with at least some immature eggs as "synovigenic." Female C. rubecula deposit a maximum number of 10 eggs per day at high host densities under semifield conditions (Nealis, 1990). C. rubecula is an endoparasitic koinobiont. The host larva continues to live during parasitoid development but dies shortly after the parasitoid larva has left the host's body.

Female C. rubecula used in the experiments originated from commercial broccoli fields near Adelaide, South Australia. In the rearing procedure, fe- 
males were allowed to parasitize second-instars Pieris rapae L. (Lepidoptera: Pieridae), feeding on cabbage plants. Cabbage plants (Brassica oleracea L. cv. "Green Coronet," Yates) were grown in 12.5-cm pots under glasshouse conditions until carrying 4-6 mature leaves. Plants with hosts were available in 25-cm-wide and 35-cm-high rectangular cages (made out of aluminum frames covered with gauze). Light and temperature conditions were set to $14 \mathrm{~L}: 10 \mathrm{D}$ and $25^{\circ} \mathrm{C}$. Wasp cocoons were collected from the rearing cages and kept in a clear, ventilated 2-L plastic container until adult emergence. As about $90 \%$ of adults emerge within a few hours after onset of light in the morning, newly emerged females were separated from the cocoon stock about $3 \mathrm{~h}$ after this event to allow time for mating and to obtain a uniform age group. After this procedure females were held in pairs in a clear $0.7-\mathrm{L}$ plastic container with a cotton wick soaked in water and a piece of paper towel as resting place until used for the experiment.

Pak choi plants (Brassica rapa var. chiniensis) were grown in 10-cm pots in a glasshouse. As the initiation of flowering in pak choi plants can be accelerated by long daylight conditions, natural daylight was extended to $16 \mathrm{~h}$ with a plant light $(1000 \mathrm{~W}$, American metal multivapor halide lamp). Pak choi was chosen as a food plant in the experiment as it produces fragrant yellow flowers and can extend the longevity of C. rubecula wasps up to 19 days (unpublished data).

\section{Experimental Procedure}

The maximum longevity of female C. rubecula without food is only 2-3 days under the given temperature conditions and therefore 1-day-old females were chosen for the experiment. On the day prior to the experiment, all wasps were allowed to antennate $P$. rapae feeding damage and frass from one larva on a $B$. oleracea leaf and subsequently to sting this larva. After the host was stung, the wasp was returned to its container and considered as host-experienced. This procedure increases the responsiveness of C. rubecula in subsequent wind tunnel experiments (Kaiser and Carde, 1992).

To test the effect of energy state and nectar experience on female C. rubecula, wasps were allocated to three treatment groups in which wasps either were fed ad libitum, were left unfed, or had brief contact with nectar. Fed females were held in containers that contained dots of honey (Kangaroo Island "Canola"), water, and a piece of paper towel. For simplicity we fed wasps with honey and not with nectar as we wished to obtain wasps in a high-energy state. Although honey has a different sugar composition and fragrance than nectar, we assume that the behavior of sugar-satiated wasps having fed from either honey or nectar will not differ in respect to a preference for hosts over a food source. Unfed wasps were held under the same conditions but 
without honey. To obtain nectar-experienced wasps, individuals were removed from their container, allowed to climb onto a pak choi flower, and feed for $10 \mathrm{~s}$ on its nectar. This is less than $10 \%$ of the time she needs to ingest a full nectar meal on a honey source with similar sugar concentration (Siekmann et al., 2001). The time needed to gain experience is in the same order of magnitude as published elsewhere (Lewis and Takasu, 1990; Takasu and Lewis, 1993, 1996; Patt et al., 1999). Straight after the brief feeding experience, wasps experienced the scent of the flowers for an additional $20 \mathrm{~s}$. This was achieved by holding the wasp close to the flowers without allowing her to climb onto them. Also, 1 day prior to the experiment cabbage plants with 4-6 mature leaves were infested with three 2 nd-instar $P$. rapae larvae placed on three separate leaves. This was to have feeding damage and frass present in the experiment.

The observations took place in an open wind tunnel arena. The experimental arena consisted of a panel $60 \mathrm{~cm}$ wide and $140 \mathrm{~cm}$ long covered with coarse sand. Two vertical frames $(60 \times 60 \mathrm{~cm})$ covered with Terylene foil were fitted to the ends of the arena. An ordinary fan with a diameter of 40 $\mathrm{cm}$ situated in one frame, generated circular air movement by sucking air into a polyethylene tunnel under the arena that connected the bottom end with the top end of the experimental area. Air was passed through a "honey comb" - cardboard, fitted into the other frame to generate airflow in the experimental area. Average wind speed was $22.4 \mathrm{~cm} / \mathrm{s}$ and temperature was $25^{\circ} \mathrm{C}\left( \pm 1.5^{\circ} \mathrm{C}\right)$. Lighting was provided by 4 " $\mathrm{cool}$ white" fluorescent light tubes (52W, Phillips) fixed $1 \mathrm{~m}$ above the floor of the arena producing a light intensity of $8000 \mathrm{~lx}$.

Thirty minutes prior to the experiment the containers with wasps were placed into the experimental arena and left there until the experiment started to allow the wasps to adapt to the environmental conditions. Two potted cabbage plants, one plant with hosts prepared 1 day earlier (= host plant) and another plant carrying a stem of pak choi flowers (= food plant), were positioned side by side $10 \mathrm{~cm}$ apart and within $60 \mathrm{~cm}$ upwind of the release position of the wasp (Figure 1). As flowering pak choi plants grow 2-3 times higher than cabbage plants, a stem with flowers was cut and assembled with a cabbage plant in a manner that flowers were at the same height as the feeding damage on the host plant. A pak choi flower stem with approximately 10-15 single opened flowers was cut, put into a glass vial containing water, sealed with a cotton ball, and inserted into the soil of a potted cabbage plant. To control for volatiles emanating from the cut stem, a pak choi leaf was prepared in the same manner as the flower stem and added to the cabbage plant with hosts. To reduce the possibility of wasps landing randomly on one of the plants, a third cabbage plant was placed in between the test plants and the position of release. The extra plant was slightly shorter than the test plants so that it would not block the 


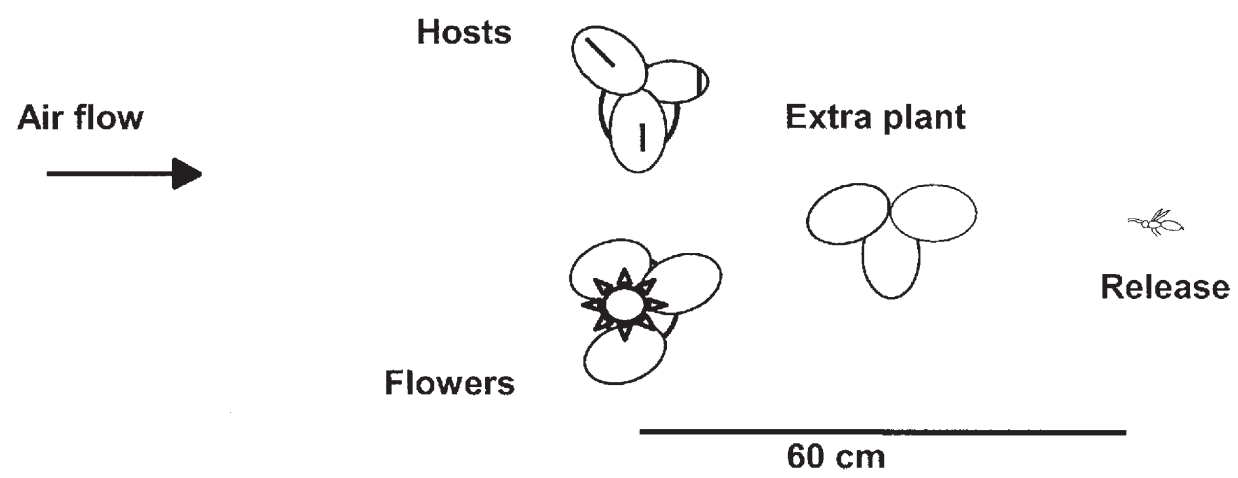

Figure 1. Positioning of plants and release of individual wasps in the wind tunnel arena.

odor plume from hosts and flowers. All replications (35 per treatment) had a balanced number of either resource plants being on either the left or right side in the arena. Before a release, the wasp was taken up by an aspirator, held close to feeding damage first and then to flowers for $5 \mathrm{~s}$ each, and then transferred to the release vial. The lip of the release vial was gently rubbed against a cabbage leaf before a wasp was put in there to be released. This glass vial measured 2 $\mathrm{cm}$ in diameter and $10 \mathrm{~cm}$ in length and was held by a metal stand at the height of hosts and flowers. The experiment started when the wasp moved to the lip of the vial and her antennae appeared outside it.

Behaviors and locations of the wasp were recorded with a handheld computer programmed with event-reading software ("The Observer," Noldus Technology, 3.1) (Table I). The preferred location was defined as the plant or location where the observed wasp settled either directly after take-off from the release vial or after a brief "stopover" at another location and exhibited searching behavior that either led to feeding or stinging a host; if neither of these events occurred the observation was terminated after $10 \mathrm{~min}$ and the preferred location recorded as the location where she spent most of the observational time. Locations were recorded as (a) cabbage plant next to release vial (= extra plant), (b) cabbage plant with feeding damage and hosts (= host plant), (c) cabbage plant with flower stem (= food plant), and (d) the rest of the arena (= other).

\section{Data Analysis}

Logistic regression was used to analyze the choices of location between different treatment groups (SAS Institute, 1995). Two independent binomial tests within each treatment group were carried out for (a) the choice between resource plants and other locations and (b) the choice between food and host plant. 
Table I. Behavior Catalogue Used for C. rubecula a Responding to Nectar and Hosts in a Wind Tunnel Arena

\begin{tabular}{|c|c|}
\hline Behavior & Description \\
\hline Flying & Any airborne activity \\
\hline Walking & $\begin{array}{l}\text { Wasp moves forward usually alternately touching the antennae to the } \\
\text { surface }\end{array}$ \\
\hline Grooming & Any action which appeared to involve cleaning of the body \\
\hline Pointing & $\begin{array}{l}\text { Stationary behavior of wasp usually facing into the wind, the antennae } \\
\text { raised and moving }\end{array}$ \\
\hline Standing still ${ }^{\mathrm{b}}$ & $\begin{array}{l}\text { Stationary behavior with no movement of any body parts, usually longer } \\
\text { than } 30 \mathrm{~s}\end{array}$ \\
\hline Feeding & $\begin{array}{l}\text { Wasp consumed liquid or solid substances by moving mouthparts over } \\
\text { the surface either during walking or standing, antennae slightly curled } \\
\text { downwards }\end{array}$ \\
\hline Attacking & $\begin{array}{l}\text { Wasp contacts host with her antennae, curled her abdomen under the } \\
\text { body and ovipositor pierces cuticle of host }\end{array}$ \\
\hline
\end{tabular}

a. M. Keller, personal communication (1998).

b. Distinction between "pointing" and "standing still" obtained by plotting log survivor values of durations (convex shapes indicated mixture of two exponentials, test for exponentiality after Haccou and Meelis (1995)).

Latency of flight and the latency of arrival on a plant with resources were analyzed using univariate survival analysis (SAS Institute, 1995). The majority of wasps displayed a latency of flight only a few seconds long, therefore Wilcoxon Test statistic was used in favor of the Log-rank Test as it stresses early differences rather than late differences between flight latencies. In respect to the latency of arrival on a resource plant, differences became apparent over longer time periods, therefore the Log rank Test was selected.

The frequencies of transition from one type of behavior to another were constructed as matrices and tested against expected frequencies (Field and Keller, 1993). The behaviors "standing still" and "pointing" were pooled and called "stationary" so that no expected values were less than 1 and no more than $20 \%$ of the expected values less than 5 . The expected values of the matrix cells were found using the iterative proportional fitting method of Goodman (1968). The deviations in the overall table were found to be statistically significant, so significant transitions were analyzed by reducing the table into a $2 \times 2$ matrix around each transition and performing a $G$ test. The significance of these individual tests was adjusted to a table-wide level of 5\% using the sequential Bonferroni method (Rice, 1989). The results of analysis of transition matrices are presented graphically in flow diagrams. Durations of behaviors were expressed in proportion of time until settling on the preferred location. These data had been arcsine-transformed before an analysis of variance was carried out (Sokal and Rohlf, 1981). 

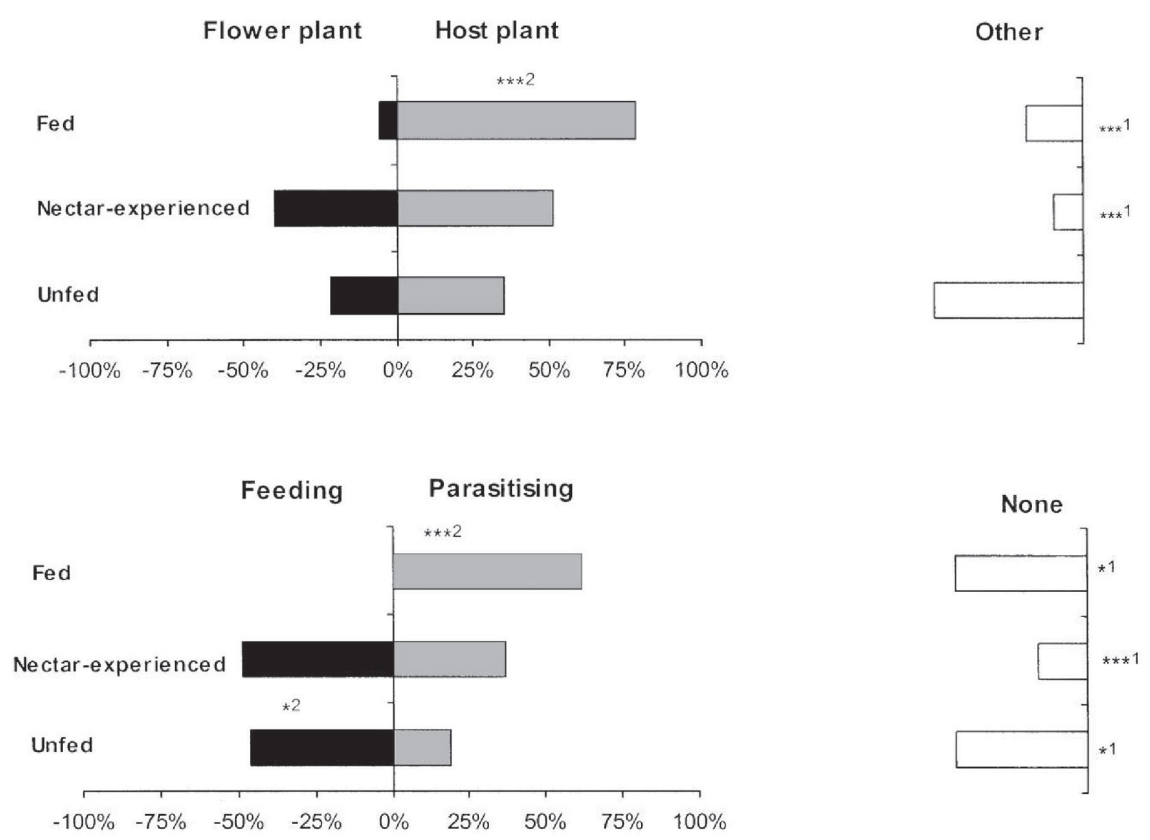

Figure 2. Response of 1-day-old female $C$. rubecula to a cabbage plant with larval $P$. rapae and a cabbage plant assembled with a stem of pak choi flowers in a wind tunnel arena. Wasps either had unlimited access to honey in the previous $24 \mathrm{~h}$ (well-fed, $n=37$ ), were allowed to taste pak choi nectar on the previous day (nectar-experienced, $n=35$ ), or were left unfed $(n=37)$. (a) Locations where wasps settled (see "Materials and Methods" for definition) and exhibited searching behavior within 10-min observation and (b) number of wasps observed feeding or stinging a host.

1. Differences between two proportions of wasps within a treatment group choosing (a) plants with resources (hosts or nectar) compared to another location in the wind tunnel (other) or (b) displaying feeding/parasitizing compared to none of them were tested with a binomial test; asterisks in the figure under title (a) "other" and (b) "none" indicate that significantly less wasps chose an area somewhere else in the wind tunnel or displayed no feeding nor parasitizing, respectively.

2. Differences in two proportions of wasps within a treatment group (a) choosing either hosts of flowers or (b) displaying either feeding or parasitizing were tested with a second Binomial Test. Asterisks above bars indicate that significantly more wasps (a) responded to a particular location or (b) displayed more feeding/parasitization events.

\section{Results}

\section{Choice of Location}

The internal state of female $C$. rubecula affected the response to hosts and flowers (logistic regression: L-R $\chi^{2}{ }_{4}=26.95 . P<0.0001$ ). The majority of 
well-fed wasps settled on the host plant whereas a higher proportion of unfed wasps and nectar-experienced wasps flew to the flowers (Figure 2a). A preference for either the flowers or hosts could not be detected in the two latter groups. Compared to unfed wasps, those with nectar experience exhibited a stronger response to both resources (logistic regression: L-R $\chi_{2}^{2}=$ $8.81, P=0.012)$. The majority of nectar-experienced wasps flew to the resource plants and settled on the host plant and food plant in nearly equal proportions. In contrast, nearly half of the number of unfed wasps remained in other areas of the wind tunnel such as on the release vial, the floor of the arena, or the extra plant (Figure 2a). As a consequence of the chosen location, fewer wasps from the starvation treatments attacked hosts than wellfed wasps, but rather exhibited feeding behavior within 10 min of observation (logistic regression: L-R $\chi^{2}{ }_{4}=37.59, P<0.001$; Figure $2 b$ ). Interestingly, hungry wasps were observed feeding not only on the nectar of the pak choi flowers, but also scraping their mouthparts over areas apparently free of sugars such as cabbage leaves, the floor of the wind tunnel arena, and the stand of the release vial.

\section{Effect of Starvation and Nectar Experience on Searching Behavior}

Initially, the analysis of behavior was conducted as a function of internal state and chosen location (food plant or host plant). As no significant differences could be found in regard to chosen location, data were pooled to compare the behavior as a function of the wasp's state only. Generally, well-fed and nectar-experienced wasps shared most of the behavioral pattern shown in locating the resource plants. Unfed wasps behaved differently to nectar-experienced and well-fed wasps, as they showed a longer latency of flight (univariate survival analysis, Wilcoxon test: $\chi_{2}^{2}=15.31, P=0.0005$ ) (Figure 3 ) and needed more time to arrive on a plant with resources (univariate survival analysis, Wilcoxon test: $x_{2}^{2}=5.057, P=0.079$, but see results of pairwise comparison in Figure 4). This indicates an increasingly delayed response to cues from flowers or hosts in unfed wasps, but not in nectar-experienced wasps. Unfed wasps also spent less time flying in comparison to well-fed and nectar-experienced wasps (Figure 5), indicating a behavior reducing energy expenditure. Significant differences among treatment groups in the average proportional time spent on walking and being stationary while locating resources were also found (Table 2). The most coordinated behavior in response to plants with resources was exhibited by nectar-experienced wasps, followed closely by well-fed wasps (Figure 6). Unfed wasps exhibited increasingly random transitions between behaviors: most apparent was the random transition of flight to any of the other behaviors, which in well-fed and nectar-experienced wasps is generally followed by walking. 


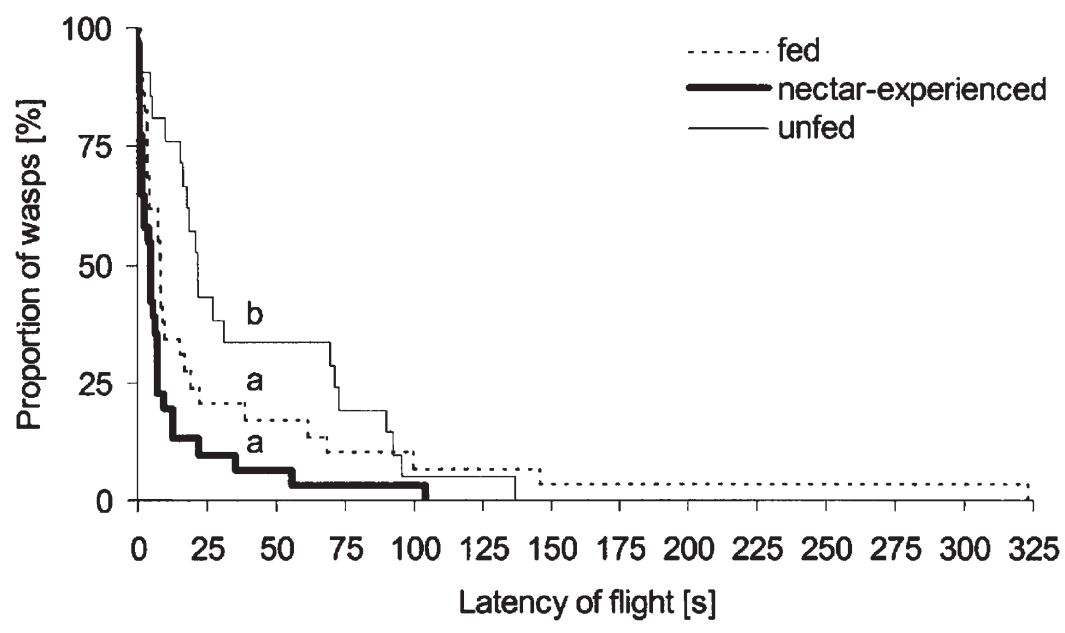

Figure 3. Latency of flight of 1-day-old female C. rubecula settling on either a plant with hosts or a plant with flowers in a wind tunnel arena. Wasps either had unlimited access to honey (well-fed, $n=31$ ), or were allowed to taste nectar (nectar-experienced, $n=32$ ), or were unfed $(n=21)$. Different letters above curves indicate statistical difference after univariate survival analysis using Wilcoxon Test, $P=0.05$ Results after pairwise comparisons were adjusted using sequential Bonferroni Method.

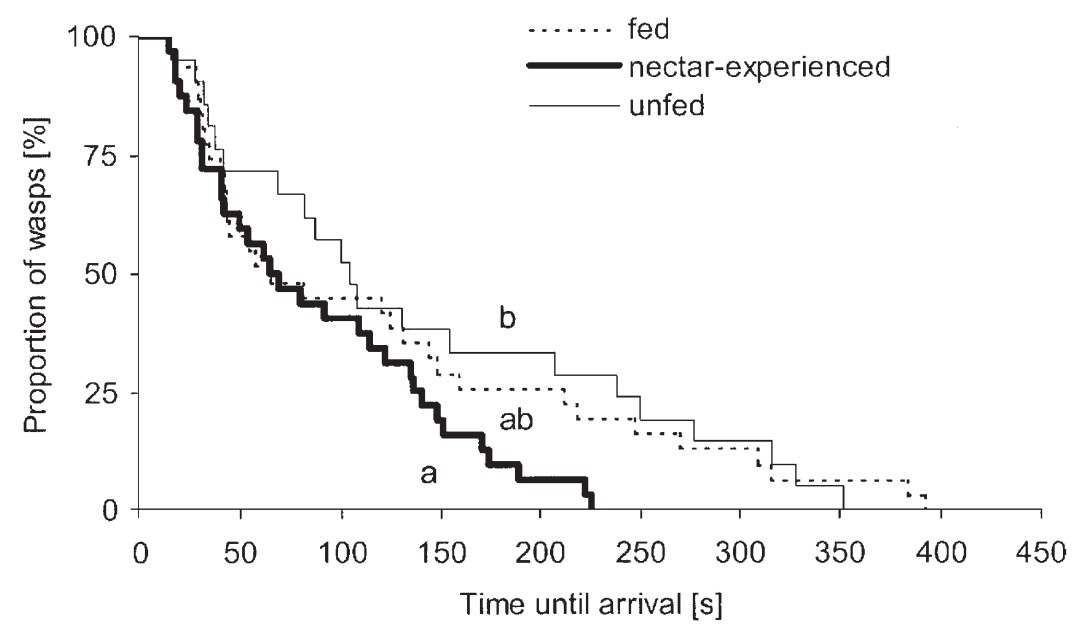

Figure 4. Time until arrival of 1-day-old female C. rubecula settling on either a plant with hosts or a plant with flowers in a wind tunnel arena. Wasps either had unlimited access to honey (well-fed, $n=31$ ), were allowed to taste nectar (nectar-experienced, $n=32$ ), or were unfed (unfed, $n=21$ ). Different letters above curves indicate statistical difference after univariate survival analysis using Log-rank Test, $P=0.05$. Results after pairwise comparisons were adjusted using sequential Bonferroni Method. 
Figure 5. Mean proportional time spent on different behaviors in female C. rubecula while locating a plant with hosts or a plant with flowers. Wasps either had unlimited access to honey in the previous 24 $\mathrm{h}$ (well-fed, $n=31$ ), were allowed to taste nectar (nectar-experienced, $n=32$ ), or were left unfed $(n=21)$.

\section{fed}

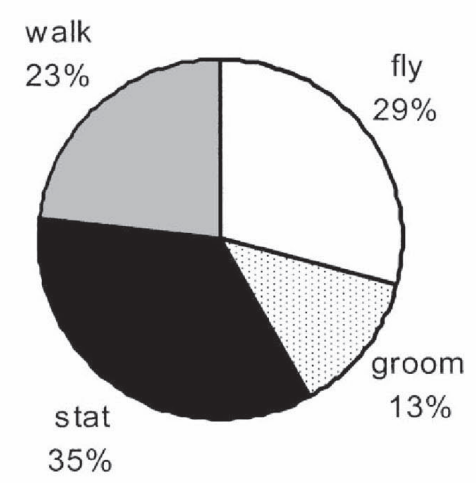

nectar - experienced

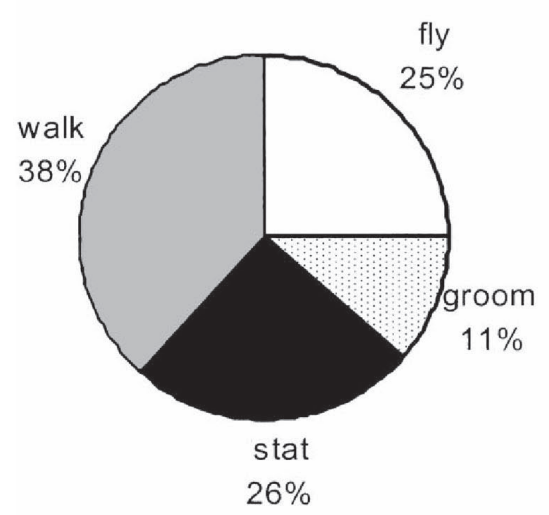

unfed

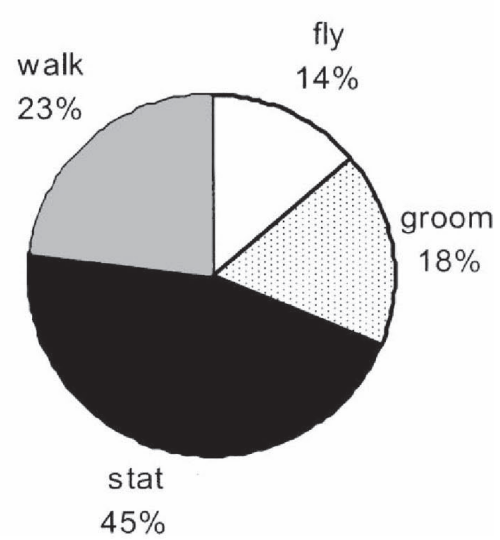


Table II. Analysis of Variance on the Proportion of Time Spent on Behaviors Among Treatment Groups

\begin{tabular}{lcc}
\hline Behavior $^{\mathrm{a}}$ & $F$ test & $P$ \\
\hline Flying & 7.131 & 0.0014 \\
Grooming & 0.949 & 0.3912 \\
Walking & 8.023 & 0.0007 \\
Stationary & 4.371 & 0.0158 \\
\hline
\end{tabular}

a. Data underwent arcsine transformation.

\section{Discussion}

Female C. rubecula wasps, differing in energy state and nectar-experience, were tested in their ability to respond to a nectar-providing plant within flying distance. At the same time hosts were available on a neighboring plant to detect a preference for hosts or sugary food. In the remainder of this paper, major findings and their significance are discussed in respect to flowers response, odors perception, and nectar foraging in the field.

\section{Response to Flowers}

Unfed 1-day-old female C. rubecula were already affected by starvation and in obvious need for food, as they behaved differently from well-fed wasps and from nectar-experienced wasps. Only $24 \%$ of unfed wasps reached the plant with flowers, whereas in Wäcker's (1994) olfactometer experiment over $60 \%$ of unfed wasps preferred flowers. The responsiveness of unfed C. rubecula females to airborne cues leading to flights to flowers or hosts within $60-\mathrm{cm}$ distance was clearly reduced. Although showing less flight activity than nectar-experienced and fed wasps, unfed wasps were still active enough to move around in the wind tunnel arena. A full egg load, a short-life expectancy, and the lack of detection of a rich food source nearby did not result in an increased response to hosts either. This suggests that starvation acts on the long-range perception of odors from distant resources.

In comparison to unfed and naïve wasps, nectar-experienced wasps were more likely to locate both flowers and hosts. In wind tunnel studies, a majority of hungry, food-experienced Microplitis croceiceps flew to a food source in the presence of hosts, with food experience taking place 20 min before the observations (Lewis and Takasu, 1990, Takasu and Lewis, 1993). In another wind tunnel experiment Takasu and Lewis (1996) reported that the memory of a scented sugar source lasted up to $6 \mathrm{~h}$ when presented on the same day but decreased substantially when presented 24 and $48 \mathrm{~h}$ later. In the present study nectar ex- 


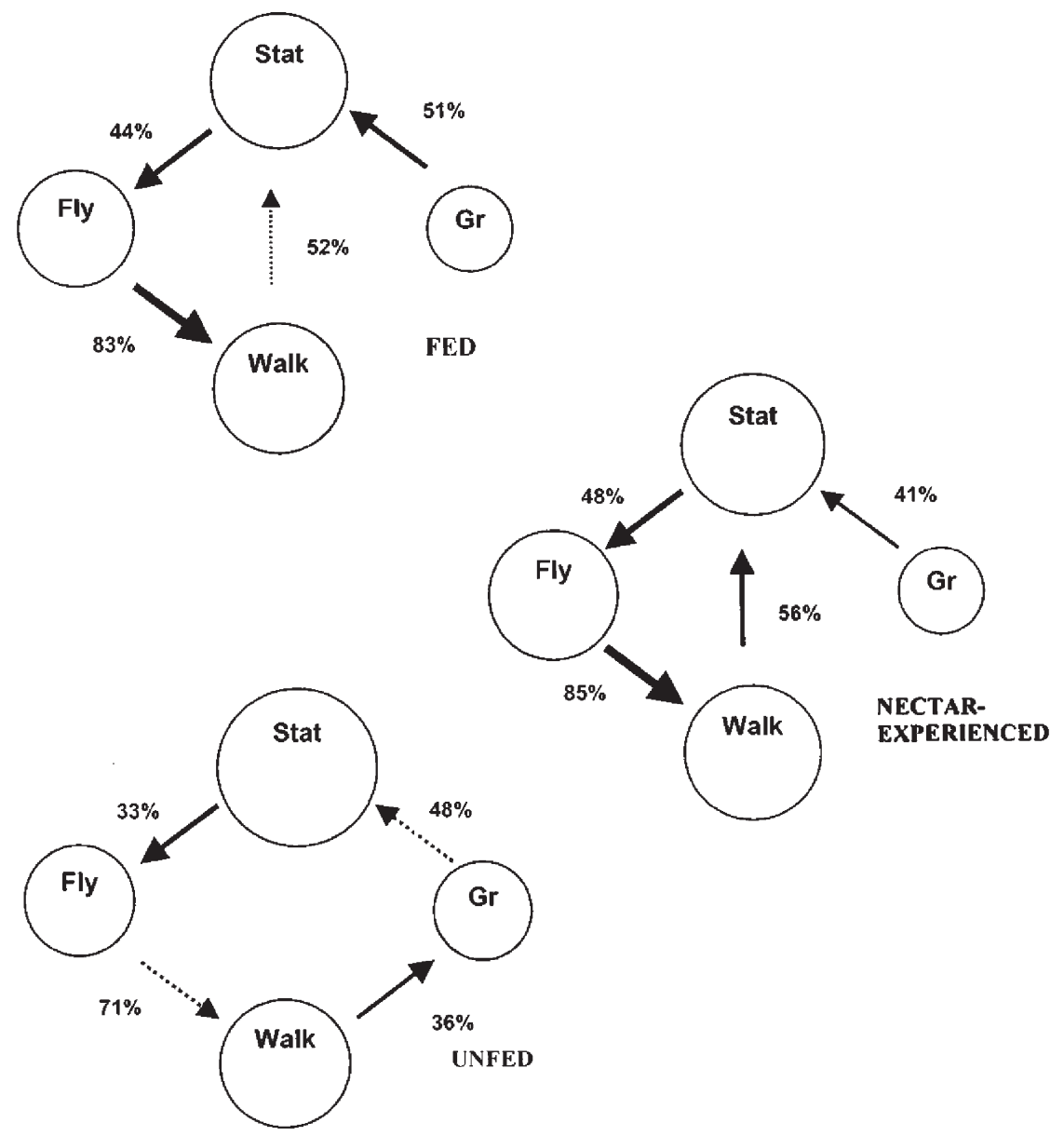

Figure 6. Flow diagrams showing the transition of behavior in 1-day-old C. rubecula females while locating a plant with hosts or a plant with nectar. Wasps either had unlimited access to honey (fed, $n=31$ ), were allowed to taste nectar (nectar-experienced, $n=32$ ), or were unfed $(n=21)$. Areas of circles in the diagrams are proportional to the relative frequency of each behavior. The arrows represent the significant behavioral flows $(P<0.05)$ (\% of transitions from given behavioral elements shown); the widths of arrows are proportional to the standardized residuals of positive deviations from expected values; standardized residual $=($ observed - expected $) /$ expected $^{1 / 2}$. Dotted arrows present marginal significance, as original $P$ values for transition were $P=0.05$ before Bonferroni adjustment but not after. Behaviors abbreviated as stat $=$ stationary, fly $=$ flying, walk $=$ walking, gr $=$ grooming.

perience took place on the previous day approximately $19 \mathrm{~h}$ before the observation. In this time the memory of food may have lost its strength, but was still strong enough to keep female $C$. rubecula responsive to their environment. Apart from time passed after encountering the odor source the success linked 
with it and the odor concentration will affect the waning of the responsiveness as well (Waage, 1978).

As nectar-experienced female C. rubecula were as active and successful in finding resources as well-fed wasps, the question arises if sampling the food source on the previous day substantially increased their nutritional state. Although the exposure to food was kept to a minimum, it cannot be excluded that the combination of experience and a small ingestion of sugar resulted in a different behavior rather than the experience alone. However, nectar-experienced and unfed C. rubecula wasps showed the same proportion of feeding events, indicating somewhat the same degree of hunger which would support the assumption of a nearly equal nutritional state in both wasp groups.

\section{Odor Perception and Decision Making}

Sugar deprivation affects not only the mobility of insects but also the functioning of the neural network important for information processing (Chippendale 1978). Initial stages of starvation have been found to increase and late stages of starvation to decrease the sensitivity to food-associated odors in beetles and tsetse flies (White, 1989; Den Otter et al., 1991). Results in the present study were consistent with these findings: states of energy and nectar experience seem to alter odor sensitivity in C. rubecula in different ways. One-dayold unfed females exhibited a reduced sensitivity to odors in general. In contrast, a brief nectar encounter seemed to increase the sensitivity to odors from flowers.

Finally, the behavioral response to an odor mixture might depend not only on the information-processing capabilities of the insect, but also on the relative proportions of odor concentrations. The ratio of flower odor concentration to host odor concentration could favor a response to either of them. In this experiment unfed and nectar-experienced wasps did not exhibit a preference for any of the resource plants. This could point to a balanced odor concentration from nectar and hosts. A change in host or flower density might yield a different outcome. The relative concentration of hosts and nectar cues in the field may shape the foraging strategies of wasps, rather than "hunger" alone. For example, a high density of hosts produces a high concentration of volatiles attractive to wasps (Kaiser and Carde, 1992; Geervliet et al., 1998). This could "mask" the odors of flowers present in the same area. However, the presence or the absence of cues, rather than the relative concentrations of cues, seems to have the greatest importance in honey bee odor perception (Breed and Julian, 1992). In regard to this hypothesis, a change of resource densities in the present experiment would not alter the outcome of the wasp's choices. The importance of qualitative versus quantitative cues in parasitoid 
choice studies needs to be investigated to clarify to what extent choices are made dependent on the strength of external stimuli rather than on the internal state.

\section{Nectar-Foraging of Parasitic Wasps in the Field}

The findings of this wind tunnel study suggest that nectar foraging in the field might be only successful if nectar plants occur in close proximity to plants with hosts. As long as energy reserves permit a nonrandom searching behavior, host foraging may always have a higher priority than food foraging and any nectar plants may be encountered opportunistically during host searching. However, after nectar experience, hungry wasps might show a greater tendency to food searching in the presence of hosts.

Advanced depletion of energy reserves seems to be linked to a decreased perception of long-range odors and decreased ability of coordinated searching behavior. With a short life span of 2-3 days under favorable temperature conditions and an even shorter time available for coordinated searching behavior, female C. rubecula seem to have little time available for host foraging before starvation sets in, which limits them to random searching of their immediate environment. However, a recent study of Casas et al. (2003) showed that the ichneumonid $V$. canescens can forage for hosts and sugary food in the field and disperse in this habitat for hours and days without running into a severe risk of energy limitation. The sugar source in this habitat identified was honeydew which suggests that it was discovered at random while searching for hosts.

The way that parasitic wasps discover flowers has practical implications for conservation biological control projects in agriculture. Flowers can provide food for parasitic wasps enabling them to live longer and parasitize more hosts. The findings of this experiment suggest that parasitoids cannot be expected to search for flowers over long distances. The success of the propagation of flowers might critically depend on their distance to host occupied sites. Field studies reporting on the effects of flowering plants on pest reduction are not conclusive, with several studies reporting a positive relationship (Powell, 1986; Jervis et al., 1993; Baggen and Gurr, 1998) and other studies reporting no effect (Kloen and Altieri, 1990; Cowgill, 1995; Bigger and Chaney, 1998; Cappuccino et al., 1999; Nicholls et al., 2000). As several species of flowering plants beneficial for parasitoid survival have been already identified (Leius, 1961; Van Emden, 1963; Maingay et al., 1991; Jervis et al., 1993; Idris and Grafius, 1995; Patt et al., 1997), the next crucial step in understanding nectar foraging in the field would be to determine distances (Topham and Beardsley, 1975) over which parasitic wasps respond to flowers and hosts. 


\section{Acknowledgments}

We thank G. Heimpel, S. Wratten, and two anonymous reviewers for Journal of Insect Behavior for comments on a previous version of the article. GS was funded by the Australian International Research Postgraduate Scholarship.

\section{References}

Baggen, R. L., and Gurr, G. M. (1998). The influence of food on Copidosoma koehleri (Hymenoptera: Encyrtidae), and the use of flowering plants as a habitat management tool to enhance biological control of potato moth, Phthorimaea operculella (Lepidoptera: Gelechiidae). Biol. Control 11: 9-17.

Bigger, D. S., and Chaney, W. E. (1998). Effects of Iberis umbellata (Brassicacea) on insect pests of cabbage and on potential biological control agents. Environ. Entomol. 27: 161-167.

Breed, M. D., and Julian, G. E. (1992). Do simple rules apply in honey-bee nestmate discrimination? Nature 357: 685-686.

Cappuccino, N., Houle, M.-J., and Stein, J. (1999). The influence of understorey nectar resources on parasitism of the spruce budworm Choristoneura fumiferana in the field. Agric. Forest Entomol. 1: 33-36.

Casas, J., Driessen, G., Mandon, N., Wielaard, S., Desouhant, E., Alphen, J. van, Lapchin, L., Rivero, A., Christides, J. P., and Bernstein, C. (2003). Energy dynamics in a parasitoid foraging in the wild. J. Anim. Ecol. 72: 691-697.

Chippendale, G. M. (1978). The functions of carbohydrates in insect life processes. In Rockstein, M. (ed.), Biochemistry of Insects, Academic Press, New York, pp. 2-55.

Cowgill, S. E. (1995). Influence of the chickpea cropping system on Helicoverpa armigera (Lep.: Noctuidae) populations and their rate of parasitism by Campoletis chloridae (Hym.: Ichneuminidae). Entomophaga 40: 307-315.

Den Otter, C. J., Tchicaya. T., and Schutte, A. M. (1991). Effects of age, sex and hunger on the antennal olfactory sensitivity of tsetse flies. Physiol. Entomol. 16: 173-182.

Dethier, V. G. (1982). Mechanism of host-plant recognition. Entomol. Exp. Appl. 31: 49-56.

Field, S. A., and Keller, M. A. (1993). Courtship and intersexual signaling in the parasitic wasp Cotesia rubecula (Hymenoptera: Braconidae). J. Insect Behav. 6: 737-750.

Fletcher, J. P., Hughes, J. P., and Harvey, I. F. (1994). Life expectancy and egg load affect oviposition decisions of a solitary parasitoid. Proc. R. Soc. Lond. [Biol] 258: 163-167.

Goodman, L. A. (1968). The analysis of cross-classified data: Independence, quasi-independence and interactions in contingency tables with or without missing entries. J. Am. Stat. Assoc. 63: 1091-1131.

Geervliet, J., Ariens, S., Dicke, M., and Vet, L. (1998). Long-distance assessment of patch profitability through volatile infochemicals by the parasitoids Cotesia glomerata and Cotesia rubecula (Hymenoptera, Braconidae). Biol. Control 11: 113-121.

Haccou, P., and Meelis. E. (1995). Statistical Analysis of Behavioral Data, Oxford University Press, New York.

Hagley, E. A. C., and Barber, D. R. (1992). Effect of food sources on the longevity and fecundity of Pholetesor ornigis (Weed) (Hymenoptera: Braconidae). Can. Entomol. 124: 341-346.

Heimpel, G. E., Rosenheim, J. A., and Kattari, D. (1997). Adult feeding and lifetime reproductive success in the parasitoid Aphytis melinus. Entomol. Exp. Appl. 83: 305-315. 
Heimpel, G. E., Mangel, M., and Rosenheim, J. A. (1998). Effects of time limitation and egg limitation on lifetime reproductive success of a parasitoid in the field. Am. Nat. 152: 273- 289.

Idris, A. B., and Grafius. E. (1995). Wildflowers as nectar source for Diadegma insulare (Hymenoptera: Ichneumonidae). a parasitoid of diamond back moth (Lepidoptera: Yponomeutidae). Environ. Entomol. 24: 1726-1735.

Jervis, M. A., Kidd, N. A. C., and Heimpel, G. E. (1996). Parasitoid adult feeding behaviour and biocontrol-A review. Biocontrol News Informat. 17: 11N-26N.

Jervis, M. A., Kidd, N. A. C., Fitton, M. G., Huddleston, T., and Dawah, H. A. (1993). Flower-visiting by hymenopteran parasitoids. J. Nat. His. 27: 67-105.

Jervis, M. A., Heimpel, G. E., Ferns, P. N., Harvey, J. A., and Kidd, N. A. C. (2001). Life-history strategies in parasitoid wasps: A comparative analysis of 'ovigeny.' J. Anim. Ecol. 70: 442- 458 .

Kaiser, L., and Carde, R. T. (1992). In-flight orientation to volatiles from the plant-host complex in Cotesia rubecula (Hym.: Braconidae): Increased sensitivity through olfactory experience. Physiol. Entomol. 17: 62-67.

Kloen, H., and Altieri, M. A. (1990). Effect of mustard (Brassica hirta) as a non crop plant on competition and insect pests in broccoli (Brassica olearacea). Crop Protect. 9: 90-96.

Leius, K. (1961). Influence of food on fecundity and longevity of adults of Itoplectis conquisitor (Say) (Hymenoptera: Ichneumonidae). Can. Entomol. 93: 771-780.

Leius, K. (1967). Food sources and preferences of adults of a parasite, Scambus buolianae (Hym.: Ichn.), and their consequences. Can. Entomol. 99: 865-871.

Lewis, W. J., and Stapel, J. O. (1998). Understanding how parasitoids balance food and host needs-Importance to biological control. Biol. Control 11: 175-183.

Lewis, W. J., and Takasu, K. (1990). Use of learned odours by a parasitic wasp in accordance with host and food needs. Nature 348: 635-636.

Maingay, H. M., Bugg, R. L., Carlson, R. W., and Davidson, N. A. (1991). Predatory and parasitic wasps (Hymenoptera) feeding at flowers on sweet fennel (Foeniculum vulgare Miller var. dulce Battandir and Trabut, Apiaceae) and spearmint (Mentha spicata L., Lamiaceae) in Massachusetts. Biol. Agric. Hortic. 7: 363-383.

Morales-Ramos, J. A., Rojas, M. G., and King, E. G. (1996). Significance of adult nutrition and oviposition experience on longevity and attainment of full fecundity of Catolaccus grandis (Hymenoptera: Pteromalidae). Ann. Entomol. Soc. Am. 89: 555-563.

Nealis, V. G. (1986). Responses to host kairomones and foraging behavior of the insect parasite Cotesia rubecula (Hymenoptera: Braconidate). Can. J. Zool. 64: 2393-2398.

Nealis, V. G. (1990). Factors affecting the rate of attack by Cotesia rubecula (Hymenoptera: Braconidate). Ecol. Entomol. 15: 163-168.

Nicholls, C. I., Parrella, M. P., and Altieri, M. A. (2000). Reducing the abundance of leafhoppers and thrips in a northern California organic vineyard through maintenance of full season floral diversity with summer cover crops. Agric. Forest Entomol. 2: 107-113.

Patt, J., Hamilton, G., and Lashomb, J. (1999). Responses of two parasitoid wasps to nectar odors as a function of experience. Entomol. Exp. Appl. 90: 1-8.

Patt, J. M., Hamilton, G. C., and Lashomb, J. H. (1997). Foraging success of parasitoid wasps on flowers: Interplay of insect morphology, floral architecture and searching behavior. Entomol. Exp. Appl. 83: 21-30.

Powell, W. 1986. Enhancing parasitoid activity in crops. In Waage, J., and Greathead, D. (eds.), Insect Parasitoids, Academic Press, London, pp. 319-340.

Rice, W. R. (1989). Analyzing tables of statistical tests. Evolution 43: 223-225. 
Rivero, A., and Casas, J. (1999). Incorporating physiology into parasitoid behavioral ecology: The allocation of nutritional resources. Res. Popul. Ecol. 41: 39-45.

SAS Institute (1995). JMP - Statistics and Graphics Guide. Version 3.1, SAS Institute, Inc., Cary. NC.

Sengonca, C., and Peters, G. (1993). Biology and effectiveness of Apanteles rubecula Marsh. (Hym., Braconidae), a solitary larval parasitoid of Pieris rapae (L.) (Lep., Pieridae). J. Appl. Entomol. 115: 85-89.

Siekmann, G., Tenhumberg, B., and Keller, M. A. (2001). Feeding and survival in parasitic wasps: Sugar concentration and timing matter. Oikos 95: 425-430.

Sirot, E., and Bernstein, C. (1996). Time sharing between host searching and food searching in parasitoids: State-dependent optimal strategies. Behav. Ecol. 7: 189-194.

Sokal, R. R., and Rohlf, F. J. (1981). Biometry: The Principle and Practice of Statistics in Biological research, W. H. Freeman, San Francisco.

Takasu, K., and Lewis, W. J. (1993). Host and food-foraging of the parasitoid Microplitis croceipes: Learning and physiological state effects. Biol. Control 3: 70-74.

Takasu, K., and Lewis, W. J. (1996). The role of learning in adult food location by the larval parasitoid, Microplitis croceipes (Hymenoptera: Braconidae). J. Insect Behav. 9: 265-281.

Topham, M., and Beardsley, J. W. (1975). Influence of nectar source plants on the New Guinea sugar cane weevil parasite, Lixophaga sphenophori (Villeneuve). Proc. Hawaiian Entomol. Soc. 22: 145-154.

Van Emden, H. F. (1963). Observations on the effect of flowers on the activity of parasitic Hymenoptera. Entomol. Mon. Mag. 98: 265-270.

Waage, J. K. (1978). Arrestment responses of the parasitoid, Nemeritis canescens, to a contact chemical produced by its host Plodia interpunctella. Physiol. Entomol. 3: 135-146.

Wäckers, F. L. (1994). The effect of food deprivation on the innate visual and olfactory preferences in the parasitoid Cotesia rubecula. J. Insect Physiol. 40: 641-649.

Wäckers, F. L., and Lewis, W. J. (1994). Olfactory and visual learning and their combined influence on host site location by the parasitoid Microplitis croceipes (Cresson). Biol. Control 4: 105-112.

Wäckers, F. L., and Swaans, C. P. M. (1993): Finding floral nectar and honeydew in Cotesia rubecula: Random or directed. In Proceedings of Experimental and Applied Entomology, N.E.V., Amsterdam, Vol. 4, pp. 67-72.

White, P. R. (1989). Factors affecting the antennal and behavioral responses of the sawtoothed grain beetle Oryzaephilus surinamensis to food odor and aggregation pheromone. Physiol. Entomol. 14: 349-359.

Wolcott, G. N. (1942). The requirements of parasites for more than hosts. Science 96: 317-318. 